\title{
COMPARISON OF THE SELECTED SECONDARY METABOLITE CONTENT PRESENT IN THE CANCER-BUSH LESSERTIA (SUTHERLANDIA) FRUTESCENS L. EXTRACTS
}

\author{
Shakira Shaik $^{\mathrm{a}}$, Nisha Singh ${ }^{\mathrm{a}}$, Ashley Nicholas ${ }^{\mathrm{a}}$ \\ ${ }^{a}$ School of Biological \& Conservation Sciences, University of KwaZulu-Natal, Westville Campus, Private \\ bag X54001, Durban 4000, South Africa \\ *Email: Singhni@ukzn.ac.za (N. Singh).
}

\begin{abstract}
Extracts of in vitro leaves, field leaves and seeds of the leguminous plant Lessertia frutescens were analyzed using spectrophotometric and gravimetric methods, to the effect of quantitative comparison of their phenolic, flavonoid, alkaloid and saponin contents. As compared to the field leaves and seeds, saponins were found to be most abundantly represented in in vitro leaves, followed by phenolics, flavonoids and alkaloids. The extracts were also qualitatively analyzed so as to evaluate the presence of other phytochemicals of medicinal interest. This qualitative analysis indicated the presence of tannins, phlobatannins and cardiac glycosides. Having in mind the documented therapeutic use of these phytochemicals, the results of this study offer a strong rationale for further animal and clinical investigations of $L$. frutescens extracts.
\end{abstract}

Key words: alkaloids, flavonoids, phenolics, phytochemicals, saponins, spectrophotometry

\section{Introduction}

Complex secondary metabolic pathways seen in higher plants eventually result in the production of a vast assortment of chemical complexes known as the secondary metabolites (Yazaki, 2006) or phytochemicals. Although these natural compounds may not be essential for the growth and reproduction (Starmans and Nijhuis, 1996), recent technological advancements, particularly those in the fields of Molecular Biology and Biochemistry, have provided evidence of their allelochemical functions. If sessile, a plant's ability to avoid herbivore, bacterial, viral and fungal attacks is limited. Consequently, adaptive traits such as compounds capable of providing chemical-based defence have evolved in these plants so as to aid in their survival by vitue of warding off, inhibiting and destroying predators and diseases. According to Verpoorte and Memelink (2002), the primary function of these secondary metabolites is plant defence.

Secondary metabolites are structurally diverse; their classification is mainly derived from their biosynthetic pathways (Harborne, 1999). In pharmacognosy, phenolics (comprising flavonoids, tannins, coumarins, quinones and anthocyanins) are regarded as the widest spread phytochemical group, while alkaloids (containing one or more nitrogen atoms) are viewed upon as a more genera- and species- specific (Bourgaud, 2001); terpenoids (comprising triterpenes, steroids, saponins and cardiac glycosides) are considered to be the phytochemicals having the most diverse chemical structure (Yazaki, 2006).

Phenolic compounds may assume a wide range of structures; from simple ones containing one aromatic ring only, to very complex polymeric forms (Trease and Evans, 1996). These compounds have been documented to inhibit UV and carcinogenic tumours (Scalbert et al, 2005) and to exhibit anti-mutagenic, anti-bacterial, anti-viral and anti-inflammatory effects (Middelton et al, 2000). Flavonoids contain free hydroxyl groups attached to the aromatic rings. Flavonoids such as rutin, present in certain buckwheat species, are known to inhibit lipid oxidation by virtue of radicals' scavenging (Jiang et al, 2007). These compounds protect against coronary heart ailments and have anti-microbial, anti-tumour and anti-inflammatory effects (Harborne and Williams, 2000). Since capable of inhibiting intestinal $\alpha$-glucosidase, phenolics and flavonoids found in eggplant also aid glucose absorption control in type 2 diabetes (Kwon et al, 2008).

Alkaloids are heterocyclic compounds with powerful physiological effects on mammals (Shamsa et al, 2008). Pyridine alkaloids like trigonelline found in Trigonella foenum-graecum, have been reported to be useful in diabetes management (Liu, et al, 2010). Saponins (a class of terpenoids) are amphipathic compounds composed of saccharide attached to a steroid or tripterpene. Saponins such as quercetine and soyasaponin, present in certain Trifolium species, are beneficial to human nutrition (Oleszek and Stochmal, 2002). Other representatives of this class, like bidesmosidic saponins present in Mimusops laurifolia, have found use in cosmetics and detergents because of their foaming ability (Eskander et al, 2006).

For the purposes of this study, Lessertia frutescens, a plant of medicinal importance, was selected for phytochemical profiling. This plant has been used in traditional medicine for centuries by diverse cultural groups residing in southern Africa in order to manage a wide variety of ailments including gynaecological, gastrointestinal, urogenital and musculoskeletal disorders; insofar, no adverse treatment outcomes have been recorded (Xaba and Notten, 2003). Numerous reports have documented an 
anti-oxidant (Tai et al, 2004), stress-relieving (Prevoo et al, 2008), hypoglycaemic (Chadwick et al, 2007), anti-mutagenic (Reid et al., 2006), and anti-tumour (Stander et al. 2007) properties of $L$. frutescens extracts. These extracts have also been reported to inhibit HIV target enzymes (Hartnett et al, 2005). However, little is known about the bioactive compounds that facilitate the acting mechanisms of these remedies. Aqueous and methanol extracts of $L$. frutescens field leaves have been shown to contain flavonoids and saponins (Van Wyk \& Albrecht, 2008; Avula et al, 2010). Nevertheless, quantitative and qualitative assessments of alkaloids, phenolics, saponins and flavonoids in the seeds or in vitro cultures of this species are very rare. Spectrophotometry has become a useful crude plant extract screening technique enabling the detection and verification of various compound classes. Data contributing to the elucidation of $L$. frutescens medicinal properties and its health-enhancing components shall vastly enhance the commercial value of these extracts. Therefore, the objective of this study was to compare phenolic, flavonoid and alkaloid content present in in vitro leaves, field leaves and seeds of $L$. frutescens using spectrophotometry, as well as to compare their saponin content using gravimetric analysis. In addition, qualitative tests were carried out so as to identify the presence of tannins, phlobatannins and cardiac glycosides.

\section{Materials and Methods Plant materials}

Three different types of material, viz. in vitro leaves, field leaves and seeds were used for chemical profiling. In vitro leaves (Sample A) were obtained from the cultures grown in our laboratory (Shaik et al, 2010), where stock plants of $L$. frutescens were verified against the specimens (W.J. Louw 2876 and R. Erasmus 198) deposited into the Ward Herbarium, University of KwaZulu-Natal, South Africa. Commercially available powdered leaves (Bee-Med Natural Herbs, South Africa) were used as the field leaf source (Sample B), while the seeds (Sample C) were obtained from Silverhill Seeds and Books, Kenilworth, South Africa. Samples A and C were dried at $60^{\circ} \mathrm{C}$ for $48 \mathrm{~h}$ in a laboratory oven and then grinded into a fine powder using a pestle and mortar.

\section{Quantitative determination of phenolics, flavonoids, alkaloids and saponins}

The extracts were concentrated using a Buchi rotary evaporator (Switzerland), while spectrophotometric measurements were completed using a Beckman DU 530 UV/VIS spectrophotometer. All analyses were done in duplicate.

\section{Phenolics}

An adaptation of the method published by Biglari et al. (2008) was used to determine phenolic content. Five grams of the samples A, B and C were separately extracted in $15 \mathrm{ml}$ of methanol at the room temperature for $5 \mathrm{~h}$ using a mechanical shaker (Labcon 3100 E, South Africa). The extracts were then filtered through a Whatman No 1 filter paper and centrifuged for $10 \mathrm{~min}$ using an Eppendorf $5810 \mathrm{R}$ (Germany) centrifuge at the rate of $5400 \mathrm{x} \mathrm{g}$. The supernatant was concentrated for $15 \mathrm{~min}$ under a reduced pressure at $40^{\circ} \mathrm{C}$ using the rotary evaporator so as to obtain a crude methanol extract. Following the evaporation, dry weights of the extracts $\mathrm{A}, \mathrm{B}$ and $\mathrm{C}$ were $0.51,1.00$, and $0.30 \mathrm{~g}$, respectively. Each evaporated extract was diluted with $5 \mathrm{ml}$ of methanol. Forty $\mu$ l of each sample were mixed with $1.8 \mathrm{ml}$ Folin-Ciocalteu reagent 10 -fold pre-diluted with distilled water, and allowed to rest at the room temperature for $5 \mathrm{~min}$. Thereafter, $1.2 \mathrm{ml}$ of $7.5 \%$-sodium bicarbonate was added to each mixture. After resting for $60 \mathrm{~min}$ at the room temperature, the absorbance of these solutions was measured at $765 \mathrm{~nm}$. Gallic acid (Sigma) was used as the standard. The concentration of total phenolic compounds was expressed as $\mathrm{mg}$ of gallic acid equivalents per $\mathrm{g}$ of dry plant weight using a Gallic acid-based calibration curve. The range covered by the calibration curve was $1-20 \mu \mathrm{g} / \mathrm{ml}$. All of the Gallic acid solutions were assayed the same way as the samples.

\section{Flavonoids}

An adaptation of the method published by Wang et al. (2008) was used to determine flavonoid content. Two and a half grams of the samples A, B and C were separately extracted in $8 \mathrm{ml}$ of methanol in a GFL 1083 water bath (Germany) and shaken under reflux for $12 \mathrm{~h}$ at $70^{\circ} \mathrm{C}$. The extracts were then filtered through a Whatman No 1 filter paper and evaporated to dryness in the rotary vacuum evaporator for $10 \mathrm{~min}$ at $40^{\circ} \mathrm{C}$. Following the evaporation, dry weights of $\mathrm{A}, \mathrm{B}$ and $\mathrm{C}$ extracts were $0.26,0.50$, and $0.15 \mathrm{~g}$, respectively. This was followed by the addition of $20 \mathrm{ml}$ of methanol so as to dissolve each of the extracts. Thereafter, $1 \mathrm{ml}$ of each methanol solution was transferred into $10 \mathrm{ml}$-volumetric flasks to which $0.3 \mathrm{ml}$ of $5 \%$ sodium nitrite was added, and left at the room temperature for $6 \mathrm{~min}$. After the addition of $0.3 \mathrm{ml}$ of $10 \%$-aluminium nitrate to each flask, the mixtures were incubated at the room temperature for another $6 \mathrm{~min}$. Following the addition of $4 \mathrm{ml}$ of $1 \mathrm{~N}$ sodium hydroxide to each flask, the final volume was attained using methanol. Further 15-min incubation at the room temperature, enabling the colouration to develop, was followed by the measurement of absorbance at $510 \mathrm{~nm}$. Rutin (Sigma) was used as the standard. Total flavonoid content was expressed as $\mathrm{mg}$ of rutin equivalents per $\mathrm{g}$ of dry plant weight using a rutin-based calibration curve. The calibration curve covered for the range of $10-100 \mu \mathrm{g} / \mathrm{ml}$. All rutin solutions were assayed the same way as the samples. 


\begin{abstract}
Alkaloids
An adaptation of the method published by Shamsa et al. (2008) was used to determine alkaloid content. Five grams of the samples A, B and C were separately extracted in $15 \mathrm{ml}$ of methanol for $24 \mathrm{~h}$ using a mechanical shaker (Labcon $3100 \mathrm{E}$, South Africa). The extracts were filtered through a Whatman No 1 filter paper, with methanol subsequently vacuum-evaporated to dryness at $45{ }^{\circ} \mathrm{C}$ for $15 \mathrm{~min}$. Following the evaporation, dry weights of $\mathrm{A}, \mathrm{B}$ and $\mathrm{C}$ extracts were $0.55,0.80$, and $0.20 \mathrm{~g}$, respectively. Thereafter, $20 \mathrm{mg}$ of each residue was dissolved in $10 \mathrm{ml}$ of $2 \mathrm{~N}$ hydrochloric acid and then filtered as described before. One $\mathrm{ml}$ of the resulting solutions was transferred into separator funnels and washed three times using $10 \mathrm{ml}$ of chloroform per washing session. The $\mathrm{pH}$ value of each solution was then adjusted to neutral using $0.1 \mathrm{~N}$ sodium hydroxide followed by the

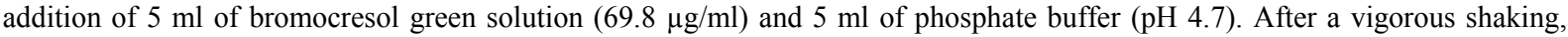
each solution was extracted separately in 1, 2,3 and $4 \mathrm{ml}$ of chloroform. Each extract was collected into a $10 \mathrm{ml}$-volumetric flask and diluted to the final volume using chloroform. The absorbance was measured at $470 \mathrm{~nm}$. Atropine (Sigma) was used as the standard. The concentration of total alkaloid compounds was expressed as $\mathrm{mg}$ of atropine equivalents per $\mathrm{g}$ of dry plant weight using an atropine-based calibration curve. The calibration curve covered for the range of $1-20 \mu \mathrm{g} / \mathrm{ml}$. All atropine solutions were assayed the same way as the samples.
\end{abstract}

Saponins

An adaptation of the method published by Shiau et al. (2009) was used to determine saponin content. Five grams of A, $\mathrm{B}$ and $\mathrm{C}$ samples were separately extracted by virtue of maceration in $50 \mathrm{ml}$ of methanol at $70{ }^{\circ} \mathrm{C}$ for $6 \mathrm{~h}$. The cooled extracts were filtered through a Whatman No 1 filter paper, with methanol vacuum-evaporated to dryness at $45^{\circ} \mathrm{C}$ for 30 min. Following the evaporation, dry weights of $\mathrm{A}, \mathrm{B}$ and $\mathrm{C}$ extracts were $0.20,0.30$, and $0.03 \mathrm{~g}$, respectively. The residues were suspended in 50 $\mathrm{ml}$ of distilled water each and extracted in three successive sessions using $100 \mathrm{ml}$ of ethyl ether per session. After removing the remaining ethyl ether from the aqueous layer by virtue of evaporation, the solutions were further extracted using $100 \mathrm{ml}$ and 50 $\mathrm{ml}$ of $n$-butanol, respectively. The $n$-butanol fractions were dried by means of evaporation. The resultant products represented the crude saponin content and were expressed as $\mathrm{mg}$ of saponin per $\mathrm{g}$ of dry plant material weight.

\title{
Qualitative determination of other phytochemical compounds
}

Samples A, B and C were tested for tannins, phlobatannins and cardiac glycosides using phytochemical tests described by Trease and Evans $(1978,1996)$. Each test result was qualified as negative (-) or positive (+).

\section{Ferric chloride test for tannins}

Half a gram of dried samples A, B and C was placed into separate test tubes. Twenty ml of distilled water were added to each test tube and boiled for $10 \mathrm{~min}$. After cooling, each extract was separately filtered through a Whatman No 1 filter paper. Thereafter, 3 drops of $0.1 \%$ - ferric chloride were added to each extract and observed for colouration.

\section{Hydrochloric acid test for phlobatannins}

Half a gram of dried samples A, B and C was placed into separate test tubes. Twenty ml of distilled water were added to each test tube and boiled for $10 \mathrm{~min}$. After cooling, each extract was separately filtered through a Whatman No 1 filter paper. Thereafter, $2 \mathrm{ml}$ of 1\%- aqueous hydrochloric acid was added to each extract and observed for colouration.

\section{Keller-Killiani test for cardiac glycosides}

Half a gram of dried samples A, B and C was placed into separate test tubes. Twenty ml of distilled water were added to each tube. After $24 \mathrm{~h}$, each extract was separately filtered through a Whatman No 1 filter paper. Thereafter, $5 \mathrm{ml}$ of each extract were treated with $2 \mathrm{ml}$ of concentrated glacial acetic acid and 2 drops of $0.1 \%$ ferric chloride solution. This mixture was then carefully added to $1 \mathrm{ml}$ of the concentrated sulphuric acid. The interface was observed for colouration.

\section{Statistical analysis}

Data are represented as the means plus/minus standard deviations of the duplicate determinations. Data were subjected to Duncan's Multiple Range Test using the SAS program (Version 6.12, SAS Institute Inc., Cary, NC, USA).

\section{Results and Discussion}

Quantitative analyses of the total saponin, alkaloids, phenolic and flavonoid contents present in different $L$. frutescens extracts were performed in duplicate; the results are presented in Table 1 and Figure 1. In all phytochemical groups profiled, the 
share of saponins in in vitro leaves, field leaves and seeds was found to be the highest $(53.34,60.00$, and $6.00 \mathrm{mg} / \mathrm{g}$, respectively), followed by phenolics $(30.18,15.09$, and $4.89 \mathrm{mg} / \mathrm{g}$, respectively) and then alkaloids $(4.52,1.58$, and $0.47 \mathrm{mg} / \mathrm{g}$, respectively). As for flavonoids, only smaller amounts were found in the above samples $(7.18,5.55$, and $1.87 \mathrm{mg} / \mathrm{g}$, respectively).

The differences in the quantity of studied phytochemicals found in in vitro and field leaf extracts may be attributed to genetic differences in the plant material, environmental conditions, harvesting season and storage conditions (Santos-Gomes et al, 2002; Biglari et al, 2008; Jiang et al, 2007). It has been reported that metabolic cell reactions may become repressed prior to phytochemical analysis (Bourgaud et al, 2001). However, the in vitro leaf extract was shown to contain significantly higher quantities of phenolics, flavonoids and alkaloids. Bourgaud et al. (2001) reported this effect to be potentially attributed to the slowdown in the allocation of carbon needed for cell built-up; should so happen, the available carbon is used for an increased phytochemical production. Furthermore, all extraction parameters were kept constant throughout the study,, but the drying method applied on the field leaves by the commercial company remains unknown.

\begin{tabular}{|lcccc|}
\hline \multicolumn{5}{|l}{ Table 1 Total content ${ }^{\mathrm{y}}$ of the selected secondary metabolites present in different $L$. frutescens extracts } \\
Extract & Phenolics & Quantity of phytochemical compounds (mg/g dry weight) \\
& & Flavonoids & Alkaloids & Saponins \\
In vitro leaves & $30.18 \mathrm{a}^{\mathrm{z}} \pm 1.16$ & $7.18 \mathrm{a} \pm 0.05$ & $4.52 \mathrm{a} \pm 0.31$ & $53.34 \mathrm{a} \pm 1.89$ \\
Field leaves & $15.09 \mathrm{~b} \pm 0.56$ & $5.55 \mathrm{~b} \pm 0.08$ & $1.58 \mathrm{~b} \pm 0.07$ & $60.00 \mathrm{a} \pm 2.83$ \\
Seeds & $4.89 \mathrm{c} \pm 0.00$ & $1.87 \mathrm{c} \pm 0.38$ & $0.47 \mathrm{c} \pm 0.08$ & $6.00 \mathrm{~b} \pm 1.41$ \\
\hline
\end{tabular}

${ }^{\mathrm{y}}$ Values expressed as means \pm standard deviations $(n=2)$

${ }^{\mathrm{Z}}$ Mean separation within columns established by Duncan's Multiple Range Test $(\mathrm{P}<0.05)$

\begin{tabular}{|l|lll|}
\hline Table 2 Qualitative determination of the selected secondary metabolites in different $L$. frutescens samples \\
Sample & $\begin{array}{l}\text { Tannin test for the } \\
\text { brownish- } \\
\text { green colour }\end{array}$ & $\begin{array}{l}\text { Phlobatannin test for the } \\
\text { bright red colour }\end{array}$ & $\begin{array}{l}\text { Cardiac glycoside test for } \\
\text { the brown ring expected to emerge at the interface }\end{array}$ \\
In vitro leaves & + & + & + \\
Field leaves & + & + & + \\
Seeds & + & + & + \\
\hline
\end{tabular}

Saponins are widespread in all legume cells and often occur in aerial parts of healthy plants in large quantities (Palazón et al, 2006). Saponin content established in this study (Table 1 and Fig. 1) mirrors these conclusions. Saponins present in $L$. frutescens appear to be stable, do not degrade easily and were therefore found in large quantities in in vitro (53.34 mg/g) and field leaves $(60.00 \mathrm{mg} / \mathrm{g})$ despite environmental and harvesting differences.

Phenolic content was higher in the leaf extracts (30.18 in in vitro and $15.09 \mathrm{mg} / \mathrm{g}$ in the field leaves) as compared to the seed extract $(4.89 \mathrm{mg} / \mathrm{g})$. Shoots and leaves were also reported to have higher phenolic content in comparison to other plant parts (Bernardi et al, 2008). The results of this study revealed the in vitro leaf extract to contain twice as much phenolics as the field leaf one. Reasons for the variations in phenolic quantity in in vitro and field leaves are said to be the result of endogenous degradation of some of the phenolic compounds, occuring after an air exposure, as well as to be the result of an increase in temperature or light exposure during field sampling (Santos-Gomes et al, 2002). Phenolic composition is also dependent on cultivation season, contamination by insects and other agents, different physiological phases and genetic profile (Bernardi et al, 2008), which may explain the lower phenolic yield from the field leaves.

Flavonoid content present in seeds is characteristically low (Oleszek and Stochmal, 2002), as was evident in this study $(1.87 \mathrm{mg} / \mathrm{g})$. Flavonoids in the in vitro leaf extract $(7.18 \mathrm{mg} / \mathrm{g})$ were significantly higher than in the field leaf extract $(5.55 \mathrm{mg} / \mathrm{g})$, which may be attributed to differences in light exposure (Hernandez et al, 2008) and to the warm temperature characteristic of growth chamber conditions of in vitro plant cultivation (Shaik et al., 2010). As indicated in the literature, it is likely that abiotic stresses arising due to the low light intensity and temperature differences during in vitro cultivation may have triggered the response mechanism in terms of an increased flavonoid production (Hernandez et al, 2008). Furthermore, the synthesis and accumulation of flavonoids can be influenced by other factors such as genotype (species and variety) and ecological conditions such as locality and harvesting period (Jiang et al, 2007).

In this study, alkaloid yields were the lowest since this group of compounds is sparsely distributed and more specific of genera and species (Bourgaud et al., 2001). The seed alkaloid content $(0.47 \mathrm{mg} / \mathrm{g})$ was significantly lower than that of the in vitro 
$(4.52 \mathrm{mg} / \mathrm{g})$ and field leaves $(1.58 \mathrm{mg} / \mathrm{g})$, probably because alkaloids are biosynthesized in leaves and, consequential to the decreased translocation, get to be found in seeds in very small amounts. Out in the wild, plants are susceptible to a variety of pathogens; this too has contributed to the reduced alkaloid production (Zehra et al, 1998). An increased alkaloid production has been reported to be the result of favourable cultivation conditions such as $\mathrm{pH}$, temperature and nutrient supply (Liu et al, 2010), coupled with specialized spatial and temporal controls (Yazaki, 2006) characteristic of an in vitro culture.

Qualitative analyses of tannins, phlobatannins and cardiac glycosides present in L. frutescens extracts were performed according to the standard phytochemical screening protocols; the results are presented in Table 2 . All three phytochemical classes were found in all extracts studied. Tannins occur widely in higher plants and are represented by two subtypes: condensed tannins (or proanthocyanidins) and hydrolysable tannins. In this study, tannins determined qualitatively were found to be of the condensed type, as verified by the formation of the red insoluble compounds called phlobatannins (or phlobaphenes) that emerge whenever condensed tannins are treated with acid (Trease and Evans, 1996). This finding supports those of other studies which have shown the condensed tannins to be commonly present in woody plants (Trease and Evans 1978, 1996). The results also revealed the presence of cardenolides, a type of cardiac glycosides that has been used to treat congestive heart failure (Braga et al, 1997). Both tannins and cardiac glycosides are found in plants and are used as protection against herbivores (Chavan et al., 2001). The literature (mentioned above) is full of reports that validate the importance of $L$. frutescens extracts' medicinal use. Anecdotal information (Xaba and Notten, 2003) outlines the usefulness and efficacy of these extracts. This study provides evidence of some of the compounds that may contribute to the medicinal value of $L$. frutescens extracts.

The aim of the present study was to validate and quantify phenolics, flavonoids, alkaloids and saponins and to authenticate the presence of tannins, phlobatannins and cardiac glycosides in in vitro leaves, field leaves and seeds of $L$. frutescens. Due to the variability of many factors including environmental conditions, harvesting season, sampling techniques, nutrient disparity and genetic differences, the extracts studied showed great differences in phytochemical yield. One of the major findings was that the in vitro extracts contained the largest quantities of all studied phytochemicals except for saponins. In addition, the presence of tannins, phlobatannins and cardiac glycosides was confirmed as well. Because of the concerns about the depletion of indigenous plants witnessed in the wild, extracts of in vitro-grown plants provide a possible alternative for bioproduction. Further research is required to evaluate the potential of in vitro biomass production; an optimized yield of medicinal compounds was proven dependent of environmental, nutritional and growth factors that can be easily maintained in the laboratory conditions. The establishment of these types of medicinal plant cultivation protocols that result in the consistent yields of bioactive compounds will render invaluable commercial and research applications possible. Indisputable presence and apparent stability of phenolics, flavonoids, alkaloids and saponins in the in vitro extracts indicated that they could be biotechnologically produced in suitable quantities.

\section{Acknowledgements}

Research funds were made available by the University of KwaZulu-Natal and the National Research Foundation. The authors are grateful to Ms Siveshni Govender for her technical assistance.

\section{References}

1. Avula B., Wang, Y.H., Smillie, T.J., Fu, X., Li, X.C., Mabusela, W., Syce, J., Johnson, Q., Folk, W., Khan, I.A. (2010). Quantitative determination of flavonoids and cycloartanol glycosides from aerial parts of Sutherlandia frutescens (L.) R. Br. by using LC-UV/ELSD methods and confirmation by using LC-MS method. J. Pharmaceut. Biomed. 52: 173-180.

2. Bernardi, A.P.M., De Matos Nunes, J., Marchioro, M.K., Rosa, L.M.G., Von Poser, G.L., Rech, S.B. (2008). Phenolic compounds profiles during ex vitro acclimatization of micro-propagated Hypericum polyanthemum. Plant Physiol. Bioch. 46: 694-700.

3. Biglari, F., AlKarkhi, A.F.M., Easa, A.M. (2008). Antioxidant activity and phenolic content of various date palm (Phoenix dactylifera) fruits from Iran. Food Chem. 107: 1636-1641.

4. Bourgaud, F., Gravot, A., Milesi, S., Gontier, E. (2001). Production of plant secondary metabolites: a historical perspective. Plant Sci. 161: 839-851.

5. Braga, F.C., Kreis, W., Récio, R.A., De Oliveira, A.B. (1997). Variation of cardenolides with growth in a Digitalis lanata Brazilian cultivar. Phytochemistry 45: 473-476.

6. Chadwick, W.A., Roux, S., Van de Venter, M., Louw, J., Oelofsen, W. (2007). Antidiabetic effects of Sutherlandia frutescens in Wistar rats fed a diabetogenic diet. J. Ethnopharmacol. 109: 121-127.

7. Chavan, U.D., Shahidi, F., Naczk, M. (2001). Extraction of condensed tannins from beach pea (Lathyrus maritimus L.) as affected by different solvents. Food Chem. 75: 509-512.

8. Eskander, J., Lavaud, C., Pouny, I., Soliman, H.S.M., Abdel-Khalik, S.M., Mahmoud, I.I. (2006). Saponins from the seeds of Mimusops laurifolia. Phytochemistry 67: 1793-1799.

9. Harborne, J.B. (1999). Classes and functions of secondary products. In: Chemicals from plants: Perspectives on secondary plant products, Walton NJ, Brown DE (Eds.). Imperial College Press: UK. 
10. Harborne, J.B., Williams, C.A. (2000). Advances in flavonoid research since 1992. Phytochemistry 55: $481-504$.

11. Hartnett, S.M., Oosthuizen, V., Van de Venter, M. (2005). Anti-HIV activities of organic and aqueous extracts of Sutherlandia frutescens and Lobostemon trigonus. J. Ethnopharmacol. 96: 113-119.

12. Hernandez, I., Alegre, L., Van Breusegem, F., Munné-Bosch, S. (2008). How relevant are flavonoids as antioxidants in plants? Trends Plant Sci. 14: 125-132.

13. Jiang, P., Burczynski, F., Campbell, C., Pierce, G., Austria, J.A., Briggs, C.J. (2007). Rutin and flavonoid contents in three buckwheat species Fagopyrum esculentum, F. tataricum, and F. homotropicum and their protective effects against lipid peroxidation. Food Res. Int. 40: 356-364.

14. Kwon, Y.I., Apostolidis, E., Shetty, K. (2008). In vitro studies of eggplant (Solanum melongena) phenolics as inhibitors of key enzymes relevant for type 2 diabetes and hypertension. Bioresource Technol. 99: 2981-2988.

15. Liu, Y.H., Liang, Z.S., Chen, B., Yang, D.F., Liu, J.L. (2010). Elicitation of alkaloids in in vitro PLB (protocorm-like body) cultures of Pinella ternata. Enzyme Microb. Tech. 46: 28-31.

16. Middelton, E.J., Kandaswami, C., Theoharides, T.C. (2000). The effects of plant flavonoids on mammalian cells: implications for inflammation, heart disease and cancer. Pharmacol. Rev. 52: 673-839.

17. Oleszek, W., Stochmal, A. (2002). Triterpene saponins and flavonoids in the seeds of Trifolium species. Phytochemistry 61: 165-170.

18. Palazón, J., Moyano, E., Bonfill, M., Osuna, L.T., Cusidó, R.M., Piňol, M.T. (2006). Effect of organogenesis on steroidal saponin biosynthesis in calli cultures of Ruscus aculeatus. Fitoterapia 77: 216-220.

19. Prevoo, D., Swart, P., Swart, A.C. (2008). The influence of Sutherlandia frutescens on adrenal steroidogenic cytochrome P450 enzymes. J. Ethnopharmacol. 118: 118-126.

20. Reid, K.A., Maes, J., Van Staden, J., De Kimpe, N., Mulholland, D.A., Verschaeve, L. (2006 . Evaluation of the mutagenic and antimutagenic effects of South African plants. J. Ethnopharmacol. 106: 44-50.

21. Santos-Gomes, P.C., Seabra, R.M., Andrade, P.B., Fernandes-Ferreira, M. (2002). Phenolic antioxidant compounds produced by in vitro shoots of sage (Salvia officinalis L.). Plant Sci. 162: 981-987.

22. Scalbert, A., Johnson, I.T., Saltmarsh, M. (2005). Polyphenols, antioxidants and beyond. Am. J. Clin. Nutr. 81: 215217.

23. Shaik, S., Dewir, Y.H., Singh, N., Nicholas, A. (2010). Micropropagation and bioreactor studies of the medicinally important plant Lessertia (Sutherlandia) frutescens L. S. Afr. J. Bot. 76: 180-186.

24. Shamsa, F., Monsef, H., Ghamooshi, R., Verdian-rizi, M. (2008). Spectrophotometric determination of total alkaloids in some Iranian medicinal plants. Thai J. of Pharm. Sci. 32: 17-20.

25. Shiau, I.L., Shih, T.L., Wang, Y.N., Chen, H.T., Lan, H.F., Lin, H.C., Yang, B.Y., Ko, C.H., Murase, Y. (2009).

Quantification for saponin from soapberry (Sapindus mukorossi Gaertn) in cleaning products by a chromatographic and two colorimeteric assays. J. Fac. Agr. Kyushu U. 54: 215-221.

26. Stander, B.A., Marais, S., Steynberg, T.J., Theron, D., Joubert, F., Albrecht, C., Joubert, A.M. (2007). Influence of Sutherlandia frutescens extracts on cell numbers, morphology and gene expression in MCF-7 cells. J. Ethnopharmacol. 112: 312-318.

27. Starmans, D.A.J., Nijhuis, H.H. (1996). Extraction of secondary metabolites from plant material: A review. Trends Food Sci. Tech 7: 191-196.

28. Tai, J., Cheung, S., Chan, E., Hasman, D. (2004). In vitro culture studies of Sutherlandia frutescens on human tumor cell lines. J. Ethnopharmacol. 93: 9-19.

29. Trease, G.E., Evans, W.C. (1978). Trease and Evans' Pharmacognosy. (1 $1^{\text {th }}$ Edn.). Baillière Tindall: London.

30. Trease, G.E., Evans, W.C. (1996). Trease and Evans’ Pharmacognosy (14 ${ }^{\text {th }}$ Edn.). WB Saunders Company Ltd.: London.

31. van Wyk, B.E., Albrecht, C. (2008). A review of the taxonomy, ethnobotany, chemistry and pharmacology of Sutherlandia frutescens (Fabaceae). J. Ethnopharmacol. 119: 620-629.

32. Verpoorte, R., Memelink, J. (2002). Engineering secondary metabolite production in plants. Curr. Opin. Biotech. 13: 181-187.

33. Wang, Y.C., Chuang, Y.C., Hsu, H.W. (2008). The flavonoid, carotenoid and pectin content in peels of citrus cultivated in Taiwan. Food Chem. 106: 277-284.

34. Xaba, P.M., Notten, A., 2003. Sutherlandia frutescens. South African National Biodiversity Institute (SANBI). (online) Available http://www.plantzafrica.com/plantqrs/sutherfrut.htm (Accessed 12 February 2007).

35. Yazaki, K. (2006). ABC transporters involved in the transport of plant secondary metabolites. FEBS Lett. 580: 11831191.

36. Zehra, M., Banerjee, S., Naqvi, A.A., Kumar, S. (1998). Variation in the growth and alkaloid production capability of the hairy roots of Hyoscyamus albus, H. muticus and their somatic hybrid. Plant Sci. 136: 93-99. 